\title{
TREATMENT OF TRAUMATIC DENTAL INJURIES IN DENTAL DEPARTMENT: ONE YEAR STUDY Sanjeeb Chaudhary, ${ }^{1}$ Archana Gharti, ${ }^{1}$ Bhawana Adhikari ${ }^{1}$ \\ ${ }^{1}$ Department of Conservative Dentistry and Endodontics, School of Dental Sciences, Chitwan Medical College, Bharatpur, Nepal.
}

*Correspondence to: Dr. Sanjeeb Chaudhary, Department of Conservative Dentistry and Endodontics, School of Dental Sciences, Chitwan Medical College, Bharatpur, Nepal. Emai:; sanjeebchaudhary@gmail.com

\begin{abstract}
BACKGROUND: Traumatic dental injuries (TDI) are injuries involving the teeth and alveolar process of the jaw. TDIs are generally sudden and accidental and often require emergency care. Most TDIs represent dental emergencies that require immediate assessment and management. Immediate and proper management is required to minimize complications. There is a lack of studies related to TDIs in Nepal. The aim of this study was to investigate the treatment of TDls and its associated factors in patients treated at, School of Dental Sciences, Chitwan Medical College (CMC), over a oneyear period from January 2014 to December 2014. METHOD: All patients with TDIs, who attended the Department of Conservative Dentistry and Endodontics, School of Dental Sciences, CMC, over a one-year period from January 2014 to December 2014, were included in the study. RESULTS: A total of 60 patients (39 males [65\%], 21 females [35\%]) with a total no of 183 traumatized permanent teeth were analyzed in this study. With regard to the treatment of TDIs, the most common treatment provided was root canal treatment (25\%), followed by composite resin restorations (24\%), splinting (10\%), direct pulp capping (4.9\%), repositioning and splinting (3.27\%). Follow-up and monitoring only was done in (32\%) of tooth without any direct treatment. CONCLUSION: Root canal treatment was the most common treatment provided although most of the injuries were uncomplicated crown fracture. Therefore effective and timely treatment of TDIs with follow up appointments is required to reduce or avoid complications. This study emphasizes the importance of timely treatment of TDIs.
\end{abstract}

Keywords: Dental Trauma, Tooth Injuries, Traumatic dental injuries, Treatment.

\section{INTRODUCTION:}

Dentoalveolar injuries also called Traumatic dental injuries (TDI) are injuries involving the teeth and alveolar process of the maxilla or mandible. It is due to impact injury to the teeth, supporting tissues and oral cavity. TDIs are generally sudden and accidental and often require emergency care. Management of TDIs is a challenge as they often present as serious and complex injuries of the dentoalveolar system which may have an unfavorable prognosis. Most TDIs represent as dental emergencies that require immediate assessment and management.

TDI is considered an important public health problem due to its high frequency. Epidemiological studies in relation to TDIs show a high prevalence that ranges from $3.9 \%$ to $59 \% .{ }^{1,2}$ TDIs have higher prevalence rates among children and adolescents. Epidemiological studies have indicated that almost one third of adults have experienced dental trauma to the permanent dentition. ${ }^{3,4,5}$ Studies conducted in different countries report various prevalence rates for TDIs. The reason behind this variation among different studies may be associated with several factors, including type, design and methodology of study. ${ }^{6}$ Therefore comparison of one dental trauma study with another is difficult.

Age and gender are considered risk factors for TDIs. Many studies demonstrate that majority of TDIs occur in childhood and adolescence. ${ }^{1}$ A 12-year review of the literature reports that $25 \%$ of all school children experience dental trauma and $33 \%$ of adults have experienced trauma, with majority of injuries occurring before age nineteen. ${ }^{1}$ According to Lam et 
al. up to $92 \%$ of TDIs occur before the age of 34 year. 7 Studies have shown that males experience TDIs twice as often as females. International studies also agree on the higher prevalence of dental trauma in males than females in permanent dentition. Traumatic dental lesions are caused by an external impact on a tooth and its surrounding tissues. ${ }^{8}$ The etiology of TDIs varies and depends on a number of factors. ${ }^{9}$ Fall is the most common causative factor in children while road traffic accidents being the main cause in adult patients for dental trauma in the developing world.

The type and severity of TDIs depend upon the cause of injury. ${ }^{10}$ TDIs can result in a number of different types of injury involving the tooth (fracture injury) and the supporting structures (luxation injury). Uncomplicated crown fracture without pulp exposure is the most common type of injury to the permanent dentition. Luxation injuries are the most common TDIs in the primary dentition, whereas fractures injuries are more commonly reported for the permanent dentition. ${ }^{11}$

Diagnosis and treatment for TDIs are very complex because of many types of injury. (Seven fracture types and six luxation types). Each type of trauma requires specific treatment. This creates a complexity in diagnosis and treatment of TDIs, causing problems in selection of proper treatment. TDIs generally present as an emergency which requires prompt diagnosis and well timed management and treatment to minimize complications and save the affected tooth. The main aim for the immediate management of TDIs is to increase the chances of positive outcome. The treatment of TDIs should always be started as soon as possible following injury to decrease negative outcomes and to improve the prognosis. The goal of the treatment is to restore function and esthetics and decrease complications. However, the treatment modality varies according to the nature and severity of the injury.

Treatment of TDIs is challenging to clinicians. Treatment of TDI requires accurate diagnosis, proper emergency management and correct treatment with regular follow-ups. Several possible trauma scenarios and multiple treatment options make it very difficult for practitioners to provide evidencebased treatment and recommend the best possible treatment choice for the patient. ${ }^{12}$ Treatment planning becomes even more difficult in cases of combination injuries and in injuries involving multiple teeth.

The prognosis of TDIs highly depends on early and correct treatment and also on the type of injury, time before treatment and quality of treatment. 13, 14 However, TDIs are often accompanied by complications or consequences of different types and severities like: pulp necrosis, apical periodontitis, discoloration, pulp canal obliteration, root resorption and ankylosis. ${ }^{15}$ Therefore to ensure a favorable outcome proper diagnosis, treatment planning and follow up are important.

However, treatment of TDIs tends to be neglected and low rates of treatment of dental trauma are observed globally. This could be due to uncomplicated dental trauma injuries of enamel-dentin/tooth crown not being perceived as a condition needing immediate treatment. In addition to the economic burdens, TDIs can affect the quality of life of the patients. Treatment of TDI is also time-consuming and unpredictable. ${ }^{11,16,17,18}$

Epidemiological data provide information and knowledge about effective dental trauma treatment and various treatment modalities which helps dentists to make proper assessment and perform treatment more effectively. However, the number of epidemiological studies related to TDIs is comparatively less worldwide. In case of developing countries it is even fewer and neglected and lacks reliable data. ${ }^{19}$ The proportion and type of TDIs varies greatly from country to country. According to WHO, reliable data on frequency and severity of TDI are still lacking in most countries, particularly in developing countries. 6 It is also interesting to note the very negligible amount of epidemiological data in the field of TDIs in Nepal which points to lack of studies related to TDIs in Nepal.

Thus the aim of this study was to investigate the treatment of TDIs and its associated factors in the permanent dentition of patients treated at the dental department over a one-year period. This study may provide information regarding the concepts of effective treatment of TDIs and at the same time contribute to data about TDIs in Nepal. Only a few 
studies have been conducted in Nepal on TDIs. Thus, due to limitations of the existing data, the present study was conducted to assess the treatment of dental trauma in TDIs patients.

\section{METHODS}

This cross-sectional observational study was conducted at Chitwan Medical College. All patients with TDIs, who attended the Department of Conservative Dentistry and Endodontics, School of Dental Sciences, Chitwan Medical College, over a one-year period from January 2014 to December 2014 , were included in the study. A total of 60 patients (39 males [65\%], 21 females [35\%]) with a total no of 183 traumatized permanent teeth were analyzed during the course of the study.

A detailed history of all the patients was taken followed by a thorough extra and intra oral clinical examination. All teeth were carefully evaluated for trauma. During the clinical examination, findings related to TDIs were recorded. Basic radiographic investigations like intra oral periapical radiograph, orthopantomogram were carried out as per need to confirm the diagnosis. Information related to dental trauma was collected from the patients.

Although following information was recorded from each patient: Patients age and gender, etiology of trauma, type of trauma, type of traumatized tooth, number of traumatized teeth, and type of treatment provided, this study focused on the type of treatment provided to the TDIs patients. This study was ethically approved by the Institutional Review Committee, Chitwan Medical College. (Ethical Clearance No: CMC-IRC/2074/075-34).

\section{STATISTICAL ANALYSIS}

The data collected from this study was subjected to simple descriptive analysis (frequency distribution) and the statistical analysis was performed with Statistical Package for the Social Sciences version 20 (SPSS, IBM SPSS Inc, Chicago, IL). Frequencies and percentages were calculated. Data were explained as the number of cases and those cases percentages.

\section{RESULTS}

A total of 60 patients (39 males [65\%], 21 females [35\%]) in the age range of $14-60$ years, presenting with TDIs in permanent teeth and attending the Department of Conservative Dentistry and Endodontics, School of Dental Sciences, Chitwan Medical College, Bharatpur, Nepal between January 2007 and June 2012, were included in the study. A total number of 183 traumatized permanent teeth were evaluated in this study.

With regard to the treatment of TDI, the most common treatment provided was root canal treatment $(25 \%)$, followed by composite resin restorations $(24 \%)$, splinting $(10 \%)$, direct pulp capping (4.9\%), repositioning and splinting (3.27\%). Follow-up and monitoring only was done in (32\%) of tooth without any direct dental treatment. Distribution of type of treatments provided is shown in Table 1 below.

\section{DISCUSSION}

TDIs can present as simple enamel fractures to complex injury such as displacement or avulsion of teeth. The literature related to TDIs feature many studies that investigate epidemiology of dental trauma. 6 Number of studies investigating the incidence of dental traumas, related factors and treatment procedures in Nepal is limited; therefore, this study was conducted. This study intended to investigate the treatment of TDIs and associated factors. Population-based studies cannot illustrate the distribution of the treatment procedures of trauma. For this reason, the study was conducted on patients with TDIS who attended the clinical dental department for treatment. The purpose of this research was to investigate the treatment of TDIs among patients with dental trauma.

This study included patients with TDIs aged between 14 and 60 years who attended the Dept of Conservative Dentistry and Endodontics, during the one year period from January 2014 to December 2014. Most of the patients were examined clinically by the same researcher and data were collected. The present study provides information on the need of treatment with regard to TDIs.

The extent of damage to the teeth and the supporting structures following dental trauma is determined by the cause of the accident. 10, $20 \mathrm{~A}$ total of 259 injuries were seen in 60 patients. The most frequently seen type of TDIs in the present study 
were uncomplicated crown fractures 74 (28.57\%), followed by subluxation injury 50 (19.30\%). The present study found uncomplicated crown fractures to be the most prevalent type of injury in agreement with the dental trauma literature. The successful treatment of these fractures can be done with the use of composites resins restorative materials. There are studies showing that crown infractions (enamel crack) are the most common type of injury in permanent dentition. Since such patients with infarction injury do not have any complain they do not seek dental treatment. According to dental trauma literature, luxation injuries are commonly seen in primary dentition, while fracture injuries are more commonly seen in permanent dentition. ${ }^{11}$ The most frequent type of luxation injury observed was subluxation.

Complex cases of TDI are usually found in people seeking treatment or being referred to hospitals. Patients suffering trauma without symptom or complication frequently do not seek treatment or do not attend hospital. Lack of treatment after TDIs is a common cause of tooth loss. An important factor that affects the prognosis of traumatized teeth is immediate treatment after trauma. Epidemiological studies validate that the TDI treatment needs are inadequate in both developing countries and developed countries and that treatment of TDI is often neglected. On the other hand, there is lack of awareness about the treatment of TDIs. Patients tend to seek treatment only when symptoms appear which may be due to their lack of awareness about the long term consequences of TDIs. 8 Besides, treatment of TDls is difficult and expensive and sometimes may require treatment during the patient's entire life. ${ }^{10}$

The types of treatment provided to the traumatized teeth were evaluated in this study. The most frequent type of treatment provided was root canal treatment ( $n=46,37 \%$ ) probably because of patients attending late for treatment even though most of the injuries were uncomplicated crown fracture. They may not be aware of possible continuing effects of dental trauma. This is in agreement with many studies related to treatment of TDIs although direct comparison of studies is difficult. Even simple crown fractures can result in inflammation or pulp necrosis because of late treatment. ${ }^{11}$ The time lapse between injury and treatment plays a significant role in the type of treatment, because immediate care can provide a better prognosis for injured teeth.

The second most common treatment provided was composite resin restorations ( $n=44,35 \%)$ because most of the injuries were uncomplicated crown fractures involving only enamel and dentin requiring only restorative treatment. It is interesting that, in the present study only few patients with complicated crown fractures reported within few hours after injury for treatment. Direct pulp capping $(n=9,7 \%)$ was done in those cases. Sealing of dentinal tubules exposed due to fracture by restoration is important for pulp prognosis.

The study found that number of teeth that were treated with splinting was less compared to teeth with luxation injury. This might be due to late presentation of patents for treatment, exceeding the time frame needed for splinting. Splinting was done in ( $n=19,15 \%)$ of cases for luxation injury. Similarly repositioning and splinting $(n=6,4.8 \%)$ was performed for extrusive, intrusive and lateral luxation injuries also.

Immediate replantation is the best treatment for an avulsed permanent tooth. Unfortunately the tooth was already lost in cases of avulsion injury when the patient reported for treatment and no tooth was available for replantation; therefore no replantation treatment could be performed. Most of the injured teeth $(n=59)$ were advised for follow-up and monitoring after trauma without receiving any interventional treatment. Patients' lack of information about dental trauma and its consequences might also be responsible for delays in seeking treatment after injury. Since it is difficult to prevent dental injuries awareness about the importance and benefits of immediate treatment would reduce unfavorable outcome.

Information about the treatment of TDIs in patients was collected from this observational data. In conclusion, the present study found uncomplicated crown fractures to be the most prevalent type of injury and the most common treatment of TDIs provided was root canal treatment. Majority of TDIs treated were injuries for uncomplicated crown fractures. Although comparisons between studies should be done carefully due to lack of 
Chaudhary et al, Journal of Chitwan Medical College 2017; 7(22)

standardization, previous studies on TDIs have also found similar results. Unfortunately no comparisons could be made because there have been no studies regarding the treatment of TDIs in Nepal.

Most of the data related to TDIs available in the literature has been collected retrospectively from cross-sectional studies or from longitudinal studies of patient records. In this study the information was collected from the patients at the time of examination and diagnosis which generated more reliable data. The importance of the present study lies in the fact resulting from lack of epidemiologic data on TDI in the permanent dentition of Nepalese population. The result of this study is likely to provide information about management of these injuries. The ultimate aim of treatment is to minimize complications from dental trauma.

A limitation of the present study is the lack of followup therefore future prospective studies based on the follow up of these patients are needed to evaluate the efficacy of the treatment protocols. Based on our findings, future studies on clinical outcomes, complications and the long time survival rates could be conducted because more studies are needed to understand the complexities of treatment of TDIs.

\section{CONCLUSION}

Epidemiological studies are essential as they provide an evidence base for management of TDIs. Effective and timely treatment of TDIs has helped to reduce or avoid complications, expenses and time for patients. TDIs require immediate treatment with follow up appointments to reduce complications.

Table 1 Types of treatment provided for TDI patients

\begin{tabular}{lcr}
\hline Treatment Provided & Patients & Tooth \\
\hline Root Canal Treatment & 27 & 46 \\
Restoration & 28 & 44 \\
Splinting & 11 & 19 \\
Direct Pulp Capping & 8 & 9 \\
Repositioning and Splinting & 4 & 6 \\
Follow up and monitoring & 59 & \\
\hline
\end{tabular}

\section{REFERENCES}

1. Glendor U. Epidemiology of traumatic dental injuries - a 12 year review of the literature. Dent Traumatol 2008;24:603-611.

2. Lam R. Epidemiology and outcomes of traumatic dental injuries: A review of the literature. Aust Dent J 2016;61 Suppl 1:4-20.

3. Schuch HS, Goettems ML, Correa MB, Torriani DD, Demarco FF. Prevalence and treatment demand after traumatic dental injury in South Brazilian schoolchildren. Dent Traumatol 2012; 16(10):12003.

4. Kumar A, Bansal V, Veeresha KL, Sogi GM. Prevalence of traumatic dental injuries among 12- to 15-year-old schoolchildren in Ambala district, Haryana, India. Oral Health Prev Dent 2011;9(3):301-5.

5. Taiwo OO, Jalo HP. Dental Injuries in 12-year old Nigerian students. Dent Traumatol 2011;27:2304.

6. Altun C, Ozen B, Esenlik E, Guven G, Gürbüz T, Acikel C, Basak F, Akbulut E. Traumatic injuries to permanent teeth in Turkish Children, Ankara. Dent Traumatol. 2009; 25: 309-313.

7. Lam R, Abbott P, Lloyd C, Lloyd C, Kruger E, Tennant M. Dental trauma in an Australian rural centre. Dent Traumatol 2008;24:663-70.

8. Atabek D, Alaçam A, Aydintug I, Konakoglu G. A retrospective study of traumatic dental injuries. Dent Traumatol,30(2), 2014,154-61.

9. Guedes OA, Goncalves de Alencar AH, Lopes LG, Pécora JD, Estrela C. A retrospective study of traumatic dental injuries in a Brazilian dental urgency service. Brazil Dental Journal. 2010; 36: 153-157.

10. Glendor U, Marcenes W, Andreasen JO. Classification, epidemiology and etiology. In: Andreasen JO, Andreasen FM, Andersson L, editors. Textbook and color atlas of traumatic injuries to the teeth, 4th edn. Oxford: Blackwell; 2007. p. 217-54.

11. Andreasen JO, Andreasen FM, Andersson L. Textbook and color atlas of traumatic injuries to the teeth, 4th edn. Oxford: Blackwell 
Munksgaard; 2007.

12. Andreasen JO, Lauridsen E, Gerds TA, Ahrensburg SS. Dental Trauma Guide: a source of evidencebased treatment guidelines for dental trauma. Dent Traumatol. 2012; 28(2):142-7.

13. DiAngelis AJ, Andreasen JO, Ebeleseder KA, et al. International Association of Dental Traumatology guidelines for the management of traumatic dental injuries: 1. Fractures and luxations of permanent teeth. Dent Traumatol 2012;28:2-12.

14. Andersson L, Andreasen JO, Day $\mathrm{P}$, et al. International Association of Dental Traumatology guidelines for the management of traumatic dental injuries: 2. Avulsion of permanent teeth. Dent Traumatol 2012;28:88-96

15. Hecova H, Tzigkounakis V, Merlova V, Netolicky J. A retrospective study of 889 injured permanent teeth. Dent Traumatol. 2010; 26: 466-475.

16. Ramos-Jorge ML, Bosco VL, Peres MA, Nunes
ACGP. The impact of treatment of dental trauma on the quality of life of adolescents - a casecontrol study in southern Brazil. Dent Traumatol 2007; 23: 114-9.

17. Glendor U, Andersson L, Andreasen JO. Economic Aspects of Traumatic Dental Injuries. In: Andreasen JO, Andreasen FM, Andersson L, eds. Textbook and Color Atlas of Traumatic Injuries to the Teeth. 4th edn. Chapter 34. Oxford: Blackwell Munksgaard; 2007. p. 861-8.

18. Andersson L. Epidemiology of traumatic dental injuries. J Endod 2013;39:2-5.

19. Andreasen JO and Andreasen FM (2002) Dental trauma. In: Pine C (ed.) Community Oral Health, pp. 94-99. London: Elsevier Science.

20. Bastone EB, Freer JT, McNamara JR. Epidemiology of dental trauma: a review of the literature. Aust Dent J 2000;45:2-9 